\title{
Reduced Dopamine Terminal Function and Insensitivity to Cocaine Following Cocaine Binge Self-Administration and Deprivation
}

\author{
Yolanda Mateo', Christopher M Lack', Drake Morgan', David CS Roberts' and Sara R Jones*,I \\ 'Department of Physiology and Pharmacology, Wake Forest University School of Medicine, Winston-Salem, NC, USA
}

\begin{abstract}
Despite large numbers of studies describing neuroadaptations caused by chronic cocaine exposure, there remains considerable uncertainty as to whether alterations in dopamine (DA) neurotransmission are responsible for progression into an addicted state. Highintake, 24-h access cocaine self-administration (SA, 10 days) followed by an extended (7 days), but not I day deprivation period produces an increased motivation to SA cocaine as measured by a progressive ratio protocol. Following binge cocaine SA and deprivation, the status of DA terminals in the nucleus accumbens (NAc) was investigated using microdialysis in freely moving rats and voltammetry in brain slices. At I and 7 days following binge cocaine SA, baseline extracellular DA concentrations in the NAc core were decreased by 40 and $55 \%$ of control levels, in the I and 7 day deprivation groups, respectively. Acute cocaine (I.5 mg/ $\mathrm{kg}$, i.v.) administration increased extracellular DA (350\%) in the NAc core of naive animals but failed to significantly increase DA at I or 7 days following binge cocaine SA. The shell of the NAc showed a similar lack of effect of cocaine. Analysis of DA terminals in brain slices showed that cocaine was markedly less effective in inhibiting DA uptake at I and 7 days of cocaine deprivation (max. effect $40 \%$ of control). Electrically stimulated DA release was decreased at I day and further decreased at 7 days of deprivation (67 and $49 \%$ of control, respectively). The rate of DA uptake was increased (I50\% of control) following binge SA, irrespective of deprivation period. Finally, presynaptic autoreceptors were subsensitive at both time points, as measured by the ability of quinpirole, a D2-like DA receptor agonist, to inhibit DA release. Thus, the NAc was hypodopaminergic and DA terminals were less sensitive to cocaine following binge cocaine SA and deprivation.
\end{abstract}

Neuropsychopharmacology (2005) 30, |455-|463, advance online publication, 9 February 2005; doi: I 0.1038/sj.npp. 1300687

Keywords: sensitization; dopamine transporter; nucleus accumbens; withdrawal; addiction; neuroadaptation

\section{INTRODUCTION}

The development of cocaine addiction in humans begins with recreational use and evolves into a compulsive drug taking disorder. Gawin (1991) has suggested that long-term cocaine use produces 'neuroadaptations', which are responsible for an altered disposition to drug taking (Leshner and Koob, 1999; Dackis and O'Brien, 2001; Goldstein and Volkow, 2002). Much effort has therefore been devoted to documenting the various neurobiological changes found after extended cocaine exposure in animals (White and Kalivas, 1998; Bibb et al, 2001; Freeman et al, 2002; Zhou et al, 2003). The dopamine (DA) system is an obvious

\footnotetext{
*Correspondence: Dr SR Jones, Department of Physiology and Pharmacology, Wake Forest University School of Medicine, Medical Center Blvd, Winston-Salem, NC 27I57, USA, Tel: + I 3367168533 , Fax: + I 336 7l6 850।, E-mail: srjones@wfubmc.edu

Received 2 I September 2004; revised I4 December 2004; accepted 22 December 2004

Online publication: 6 January 2005 at http://www.acnp.org/citations/ Npp0 I0605040442/default.pdf
}

starting point in the search for neuroadaptations responsible for the addictive process. Pharmacological, neurochemical, and lesion experiments indicate that cocaine acts as an indirect agonist at DA synapses by blocking the reuptake of DA into the presynaptic terminal in the nucleus accumbens (NAc) and other projection areas of the ventral tegmental area (Heikkila et al, 1975; Ritz et al, 1987, Roberts et al, 1977; Koob et al, 1994; Volkow et al, 1997; Bardo, 1998; Di Chiara, 1999). Despite the evidence for the role of DA neurotransmission in the acute reinforcing effects of cocaine, it remains to be determined whether changes in the physiology of this system account for motivational changes associated with cocaine addiction.

Extracellular DA levels are tightly controlled by a variety of mechanisms, including but not limited to synthesis, release, autoreceptor activity, uptake, and metabolism (Onali and Olianas, 1989; Horn, 1990; Palij et al, 1990; Kennedy et al, 1992; Wieczorek and Kruk, 1995; Cragg and Rice, 2004). Repeated administration of cocaine produces changes in many of these measures; however, the magnitude and direction of these changes are inconsistent across 
studies, probably due to differences in route and pattern of administration, drug dose and length of treatment, and the duration of withdrawal (Kuhar and Pilotte, 1996). The challenge is to evaluate whether such changes are related to the addiction process. A variety of treatment protocols, using experimenter- or self-administered cocaine, have been used successfully to detect drug-induced neurobiological changes. Such protocols may not alter the reinforcing effects of cocaine (see Morgan and Roberts, 2004), and therefore it is premature to ascribe neuroadaptations resulting from the most common cocaine dosing procedures as substrates of the addiction process.

In an effort to define self-administration (SA) parameters that produce an augmentation in the reinforcing effects of cocaine, we have evaluated the effects of various access conditions, dosing intervals, and deprivation periods (Roberts et al, 2002; Morgan et al, 2002, 2004; Morgan and Roberts, 2004). Recently, a protocol has been identified which produces an increase in the reinforcing efficacy of cocaine reinforcement (Morgan et al, 2002, 2004). The protocol uses a discrete-trials procedure (DT4, see below) which allows 24-h access to cocaine without producing toxicity (Roberts et al, 2002) and produces a binge/ deprivation pattern of cocaine SA. Animals tested 1 day after extended access to cocaine on the DT schedule did not show changes in the reinforcing effects. Importantly, however, when tested after a 7-day drug-free period (ie deprivation), a significant augmentation in the reinforcing efficacy of cocaine was observed (Morgan et al, 2002, 2004). Thus, groups with similar binge cocaine SA experience compared before and after the extended deprivation period offer an opportunity to identify neurochemical events that correlate with changes in reinforcing efficacy.

Here we examined the effects of binge cocaine SA and deprivation on the physiology of the DA system in the NAc using microdialysis in freely moving rats and voltammetry in brain slices. Using these techniques, measures of DA release and reuptake, sensitivity of D2-autoreceptors, and sensitivity of the dopamine transporter (DAT) to cocaine were compared across groups of animals with similar histories of cocaine SA but differing periods of deprivation and therefore different motivational states. Major alterations in all of the measures of DA function were observed in the NAc 1 day following binge SA, suggesting compensations in response to chronically high extracellular DA levels. The 7-day off group showed similar changes indicating that the augmentation in the reinforcing efficacy of cocaine that developed over time could not be accounted for by changes in DA terminal function in the NAc.

\section{MATERIALS AND METHODS}

\section{Animals}

Male, Sprague-Dawley rats (Harlan, IN) weighing approximately $350 \mathrm{~g}$ at the start of the experiments were used as subjects. Throughout these experiments, rats were maintained on a reverse light/dark cycle (lights on at 1500 hours) with food (Ralston, Purina, St Louis, MO) and water available ad libitum. After a minimum 3-day acclimation period, each rat was anesthetized with a combination of ketamine (100 mg/kg, i.p.) and xylazine ( $8 \mathrm{mg} / \mathrm{kg}$, i.p.) and implanted with a chronic indwelling Silastic ${ }^{\circledR}$ cannula (0.012 in inner and 0.025 in outer diameter) into the right jugular vein. The cannula exited the skin on the dorsal surface in the region of the scapulae (Morgan et al, 2002), went through a stainless steel protective spring tether, and was attached to a counterbalanced fluid swivel mounted above the operant chamber, which allowed free movement within the chamber. Tygon tubing connected the swivel to an infusion pump (Razel Scientific Instruments, Inc., Stamford, CT). The operant chambers were $14 \times 14 \times 14 \mathrm{in}$, and served as both housing and testing chambers.

\section{Cocaine Self-Administration}

SA training began 1 day following surgery. At the beginning of each daily session, a retractable lever extended into the cage to signal session onset. Each lever press resulted in the delivery of $1.5 \mathrm{mg} / \mathrm{kg}$ cocaine (approximately $0.1 \mathrm{ml}$ of $5 \mathrm{mg}$ / $\mathrm{ml}$ cocaine over $\sim 5 \mathrm{~s}$ ). Cocaine hydrochloride (racemic mixture) was obtained from the National Institute on Drug Abuse (Rockville, MD), dissolved in sterile $0.9 \%$ saline and passed through a microfilter, and the dosages are expressed as the salt. Concurrent with the start of each injection, the lever retracted and a stimulus light was activated for $20 \mathrm{~s}$ to signal a time-out period. At 10 minutes before the start of each session, levers were retracted, syringes were refilled, and any changes in schedule conditions were carried out.

Rats were initially trained under a fixed ratio (FR) schedule with a maximum of 40 injections allowed. Each training session started at 1100 hours and lasted until 40 infusions had been self-administered, at which time the lever was retracted until the next daily session began. After the animals had established a stable daily pattern of cocaine intake for at least 5 days (40 infusions within $6 \mathrm{~h}$, and no increasing or decreasing trends in time to finish session), the schedule conditions were changed to a DT schedule of reinforcement. During these sessions, rats were given access to cocaine during 10 -min discrete trials. Trials were initiated at 15-min intervals with the introduction of a lever into the chamber. A single response resulted in a cocaine infusion, which was signaled by the illumination of a stimulus light for $20 \mathrm{~s}$. A trial was terminated and the lever retracted if an injection $(1.5 \mathrm{mg} / \mathrm{kg} / \mathrm{inj})$ was collected or if $10 \mathrm{~min}$ had elapsed. Rats received four discrete trials per hour (DT4), $24 \mathrm{~h} /$ day for 10 days. All animal procedures were approved by the Institutional Animal Care and Use Committee.

\section{Microdialysis}

Microdialysis guide-cannulas (CMA/11 guide cannula; CMA/Microdialysis AB, Stockholm, Sweden) were stereotaxically implanted in the NAc area (Core: anteroposterior, $+1.2 \mathrm{~mm}$; lateral, $2.0 \mathrm{~mm}$; ventral, $5.8 \mathrm{~mm}$; Shell: anteroposterior, $+2.0 \mathrm{~mm}$; lateral, $1.2 \mathrm{~mm}$; ventral, $6.0 \mathrm{~mm}$ ), relative to bregma and dura surface. Concentric microdialysis probes (membrane length $2 \mathrm{~mm}, \mathrm{CMA} / 11, \mathrm{CMA} /$ Microdialysis AB, Stockholm, Sweden) were implanted while animals were recovering from anesthesia. To simultaneously evaluate the effects of cocaine in the NAc core and shell, each rat was implanted with two probes, one on each side, aimed at the shell or core region. Microdialysis 
experiments were conducted in freely moving rats $\sim 24 \mathrm{~h}$ after surgery. The probes were perfused with artificial cerebrospinal fluid $(148 \mathrm{mM} \mathrm{NaCl} ; 2.7 \mathrm{mM} \mathrm{KCl} ; 1.2 \mathrm{mM}$ $\mathrm{CaCl}_{2} ; 0.85 \mathrm{mM} \mathrm{MgCl} ; \mathrm{pH} 7.4$ ) at a constant flow rate of $1.0 \mu \mathrm{l} / \mathrm{min}$. Samples were collected every $20 \mathrm{~min}$ and immediately analyzed for DA by HPLC coupled to electrochemical detection (BAS, West Lafayette, IN). Microdialysis data were calculated as the percentage change from baseline concentration, with $100 \%$ being defined as the average of the last three samples prior to drug treatment. The effect of cocaine $(1.5 \mathrm{mg} / \mathrm{kg}$, i.v.) on extracellular concentration of DA in the NAc areas was assessed by one-way or two-way analysis of variance (ANOVA) for repeated measures, with SA and deprivation history as the between-subject factor and time as the within-subject factor. Values of $p<0.05$ were considered statistically significant.

\section{Cyclic Voltammetry in Brain Slices}

Rats were killed by decapitation, the brain rapidly removed and cooled in ice-cold, preoxygenated (95\% $\left.\mathrm{O}_{2} / 5 \% \mathrm{CO}_{2}\right)$, modified Kreb's buffer containing (in $\mathrm{mM}$ ): $\mathrm{NaCl} \mathrm{126,} \mathrm{KCl}$ 2.5, $\mathrm{NaH}_{2} \mathrm{PO}_{4} 1.2, \mathrm{CaCl}_{2} 2.4, \mathrm{MgCl}_{2} 1.2, \mathrm{NaHCO}_{3} 25$, glucose 11, HEPES 20, L-ascorbic acid 0.4 and $\mathrm{pH}$ was adjusted to 7.4. Coronal slices $(400 \mu \mathrm{m}$ thick) containing the NAc were prepared with a vibrating tissue slicer (Leica VT1000S; Leica Instruments, Nussloch, Germany). Slices were kept in a reservoir of oxygenated buffer at room temperature until required. At $30 \mathrm{~min}$ before each experiment, a brain slice was transferred to a submersion recording chamber, perfused at $1 \mathrm{ml} / \mathrm{min}$ with $34^{\circ} \mathrm{C}$ oxygenated Kreb's, and allowed to equilibrate.

A cylindrical carbon fiber microelectrode was placed into the core of the NAc and a bipolar stimulating electrode was placed on the surface of the brain slice $\sim 200 \mu \mathrm{m}$ away (Budygin et al, 2001; Phillips et al, 2003). DA was evoked by a single, rectangular, electrical pulse $(300 \mu \mathrm{A}, 2 \mathrm{~ms} /$ phase, biphasic), applied every $5 \mathrm{~min}$. Extracellular DA was monitored at the carbon fiber electrode every $100 \mathrm{~ms}$ using fast-scan cyclic voltammetry (Kennedy et al, 1992) by applying a triangular waveform $(-0.4$ to +1.2 to $-0.4 \mathrm{~V} v s$
$\mathrm{Ag} / \mathrm{AgCl}, 300 \mathrm{~V} / \mathrm{s})$. Once the extracellular DA response to electrical stimulation was stable for three successive stimulations, cocaine $(0.03,0.1,0.3,1,3,10$, and $30 \mu \mathrm{M})$, or quinpirole $(1,3,10,30,100$, and $300 \mathrm{nM})$ were applied cumulatively ( 20 and $25 \mathrm{~min} /$ concentration, respectively) to the brain slice via the superfusate. Each test was performed in one slice, which served as its own precondition control.

To evaluate the effects of cocaine and quinpirole, evoked levels of extracellular DA were modeled as a balance between release and uptake (Wightman et al, 1988). The change in DA concentration with respect to time was estimated by $\mathrm{d}[\mathrm{DA}] / \mathrm{d} t=[\mathrm{DA}]_{\mathrm{p}}-V_{\text {max }} /\left(K_{\mathrm{m}} /[\mathrm{DA}]+1\right)$, where $[D A]$ is the brain extracellular concentration of DA, $[D A]_{p}$ is the change in concentration of DA at the electrode produced by each stimulus pulse, and $V_{\max }$ and $K_{\mathrm{m}}$ are Michaelis-Menten rate constants for DA uptake. In all cases, the goodness of the fits to the data was $r^{2}>0.95$.

Baseline voltammetry data were compared across groups (naïve and 1 or 7 days of deprivation) using one-way ANOVA. Data obtained after administration of cocaine or quinpirole were subjected to a two-way ANOVA with experimental group and dose of cocaine or quinpirole as the factors. When significant interactions or main effects were obtained, differences between groups were tested using Newman-Keuls post hoc tests. In all cases, statistical significance was set at $p<0.05$.

\section{RESULTS \\ Cocaine SA on a Discrete-Trials 4 (DT4) Schedule for 10 Days}

As described previously, when experimental conditions were changed to a DT4 schedule of reinforcement, animals self-administered nearly every injection for the first $18-36 \mathrm{~h}$ (ie the 'initial binge', Roberts et al, 2002); over the next several days, responding became more circadian with high levels of intake in the dark phase and with decreasing levels of intake in the light phase (Figure 1a and b). Across this 10day period, both groups of rats self-administered on average approximately 50 infusions/day, resulting in a total intake of
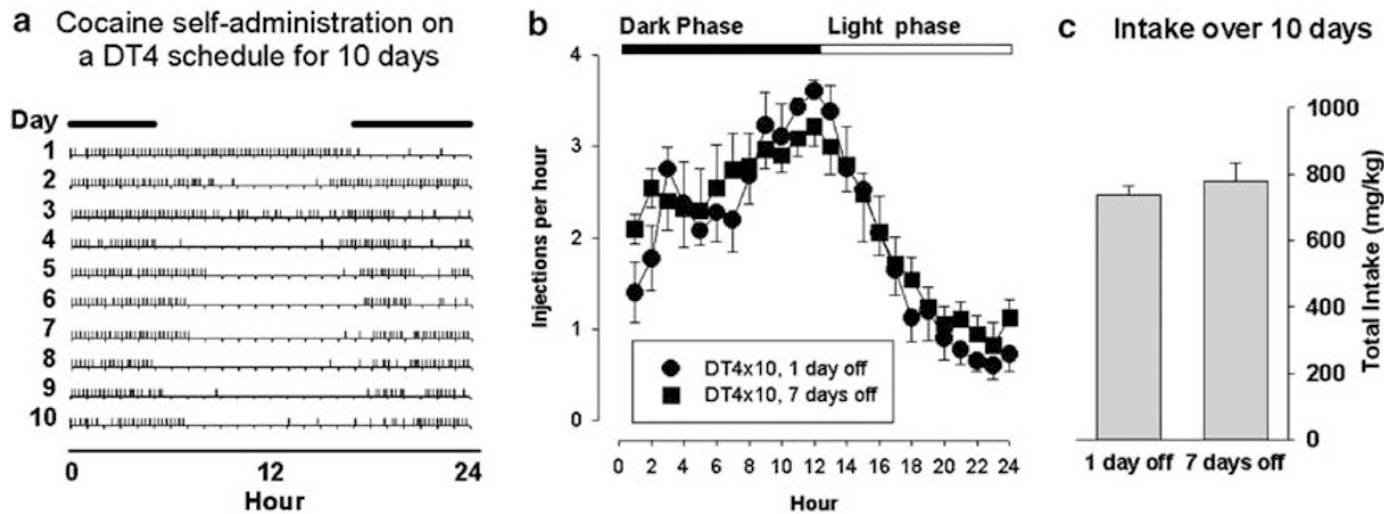

Figure I Self-administration of $1.5 \mathrm{mg} / \mathrm{kg} / \mathrm{inj}$ cocaine on a discrete-trial 4 (DT4) schedule for 10 days. (a) Daily event records (24h sessions) for an individual rat across 10 days of access to cocaine on a DT4 schedule of availability are shown. Under these conditions, animals typically take every available injection for 18-36 h (infusions indicated by tickmarks), followed by an eventual circadian pattern of responding (most SA occurs during the dark phase (indicated by dark bars above records). (b) The hourly intake of cocaine (averaged across the 10 days) for the two groups of animals. Note that the intake of cocaine increases from the beginning of the dark phase, peaks at the end of the dark phase, and decreases throughout the light phase. (c) Total intake of cocaine over the 10-day period for the two groups of rats did not differ. 
approximately $750-800 \mathrm{mg} / \mathrm{kg}$ (Figure 1c). Previous studies indicated that these patterns of SA coupled with a 7-day deprivation period result in higher levels of responding being maintained by cocaine on a progressive ratio schedule, whereas 1 day of deprivation fails to alter such responding (see Morgan et al, 2002).

Lack of Cocaine Effect in the NAc Core and Shell of Rats Following Cocaine Binge SA and Deprivation

We used microdialysis to examine the sensitivity of DA terminals to cocaine following cocaine SA and either 1 or 7 days of deprivation. Baseline extracellular DA concentrations in the NAc core of naïve animals $(44.81 \pm 2.93 \mathrm{fmol} /$ sample; $n=4$ ) were significantly higher than those in animals following cocaine SA with $1(18.09 \pm 0.27 \mathrm{fmol} /$ sample; $n=5)$ or 7 days of deprivation $(24.17 \pm 1.22 \mathrm{fmol} /$ sample; $n=8)\left(\mathrm{F}_{2,48}=8,19 ; p<0.001\right)$. Systemic administration of cocaine $(1.5 \mathrm{mg} / \mathrm{kg}$, i.v.) elevated extracellular DA concentrations in the NAc core of naïve animals but failed to induce changes in animals following cocaine binge SA with either 1 or 7 days of deprivation $\left(F_{16,116}=2.5 ; p<0.01\right)$ (Figure 2a).

To evaluate potential differences of DA terminals in the shell of the NAc following cocaine binge SA and deprivation, dual-probe microdialysis was used and two probes were simultaneously implanted in the same animal, one in the core and a second one in the contralateral shell region. Baseline extracellular DA concentrations in the NAc core and shell were not significantly different from each other $(27.39 \pm 0.9$ vs $20.52 \pm 0.73 \mathrm{fmol} / \mathrm{sample}$, respectively). Rats with a 7-day deprivation period following binge SA were chosen because they showed increased cocaine reinforcement, compared to 1 day of deprivation. In these animals, as observed before in the core of the NAc (Figure 2a), cocaine $(1.5 \mathrm{mg} / \mathrm{kg}$, i.v.) failed to elevate extracellular DA concentrations. When the contralateral NAc shell was simultaneously evaluated, no differences between brain regions (shell vs core; $\mathrm{F}_{1,48}=0.007, p=0.93$ ) and no significant interaction between groups over time $\left(\mathrm{F}_{8,48}=0.68, p=0.71\right)$ were found.

\section{DA Release in the Core of the NAc is Decreased and Clearance is Increased during Withdrawal from Cocaine Binge SA}

Transient increases in extracellular DA concentrations were evoked by single electrical pulse stimulations in slices containing the core of the NAc (Figure 3a). Electrically stimulated DA release was significantly decreased $\left(\mathrm{F}_{2,16}=15.6, p<0.001\right)$ when compared to controls by approximately $33 \%$ and $49 \%$ following cocaine SA on a DT4 schedule for 10 days coupled with a deprivation period of $1(p<0.01)$ and $7(p<0.001)$ days, respectively (Figure $3 \mathrm{~b}$ ). This decrease in DA release was greater following 7 days compared to 1 day of deprivation $(p<0.05$, Figure $3 \mathrm{~b})$. With regard to DA uptake, baseline data fit well to the kinetic model when the apparent $K_{\mathrm{m}}$ was set at the literature value of $0.16 \mu \mathrm{M}$ (Wightman et al, 1988). The value of $V_{\max }$ for naive rats was $1.6 \pm 0.1 \mu \mathrm{M} / \mathrm{s}(n=6)$. However, following cocaine SA, DA uptake rates were significantly increased $\left(\mathrm{F}_{2,18}=3.9, p<0.05\right)$ compared to
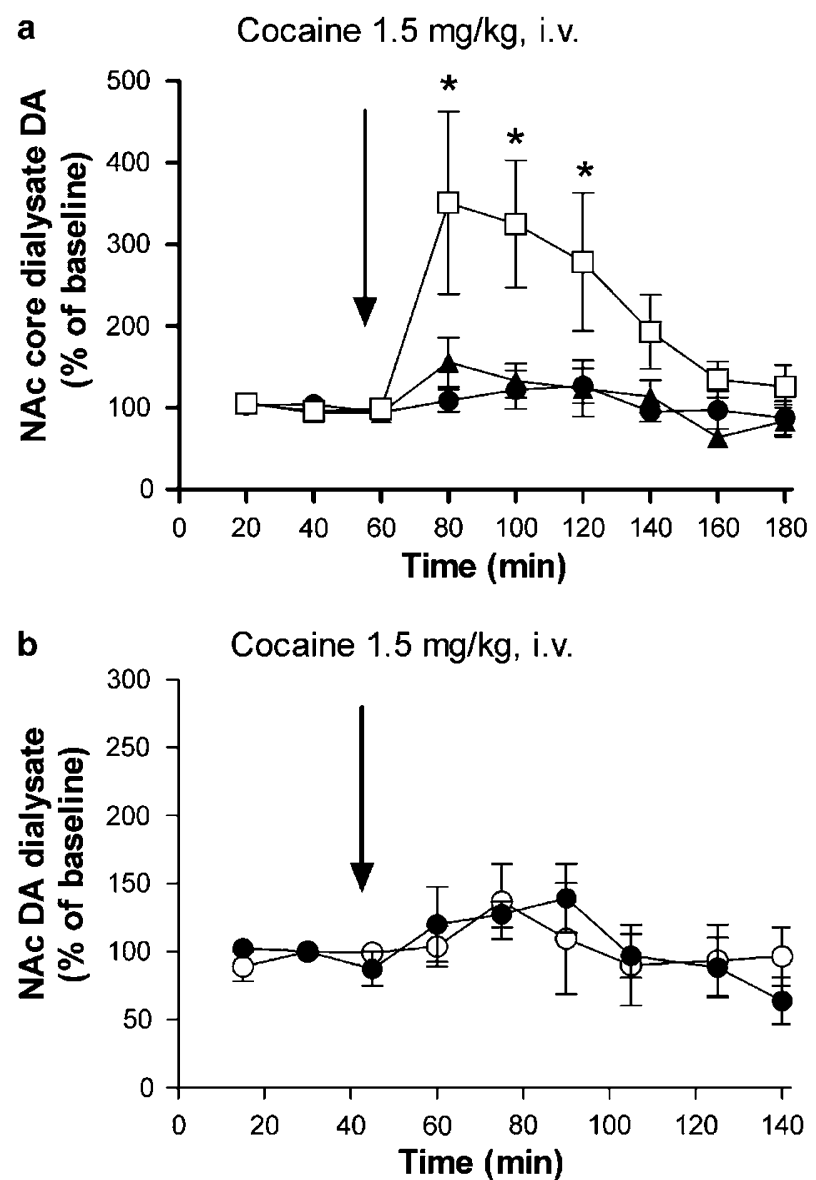

Figure 2 Lack of cocaine effect on extracellular dopamine concentrations in the core and shell of the NAc following cocaine binge SA and deprivation. (a) Effect of cocaine $(1.5 \mathrm{mg} / \mathrm{kg}$, i.v.) on extracellular concentrations of DA in the NAc core of naive animals ( $\square$ ) and rats following cocaine binge SA with I $(\mathbf{A})$ or 7 ( $)$ days of deprivation. Cocaine significantly elevated extracellular concentration of DA in naïve animals ( $p<0.01 ; n=4)$ but failed to change DA in animals following binge/ deprivation cocaine SA with $\mid(n=5)$ or $7(n=8)$ days of deprivation. *Baseline and cocaine SA groups; $p<0.05$. (b) Dual-probe microdialysis in the core and shell of the NAc of rats following cocaine binge SA. Cocaine did not increase extracellular DA either in the core $(0)$ or shell $(O)$ of the $\mathrm{NAc}(n=4)$ of rats SA for 10 and 7 days deprivation.

controls following 1 day $(2.32 \pm 0.61 \mu \mathrm{M} / \mathrm{s} ; p<0.05 ; n=6)$ or 7 days $(2.40 \pm 0.57 \mu \mathrm{M} / \mathrm{s} ; p<0.05 ; n=7)$ of deprivation (Figure $3 \mathrm{c}$ ). The fit of the data to the kinetics model were best if only a change in $V_{\max }$ was used.

\section{Cocaine is Less Efficient in Inhibiting DA Uptake Following Cocaine Binge SA and Deprivation}

To investigate the effects of cocaine on DA uptake following cocaine SA, baseline uptake rates were determined without drug, and then cocaine $(0.03-30 \mu \mathrm{M})$ was applied to brain slices cumulatively at $20-\mathrm{min}$ intervals. Following cocaine SA on a DT4 schedule for 10 days coupled with a 1 or 7 day deprivation period, cocaine exhibited a greatly diminished effect on DA uptake (Figure 4a). In general, during application of $1 \mu \mathrm{M}$ cocaine or lower concentrations, there was an increase in the amplitude and duration of the extracellular DA response to stimulation and at $10 \mu \mathrm{M}$ or 


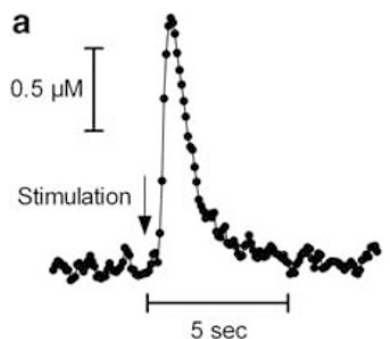

b

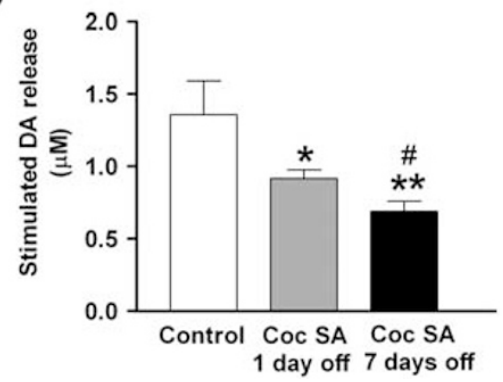

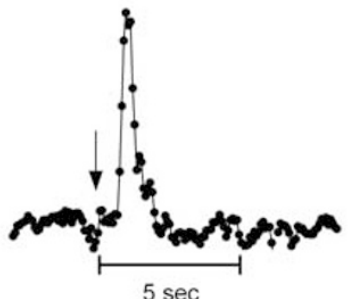

c
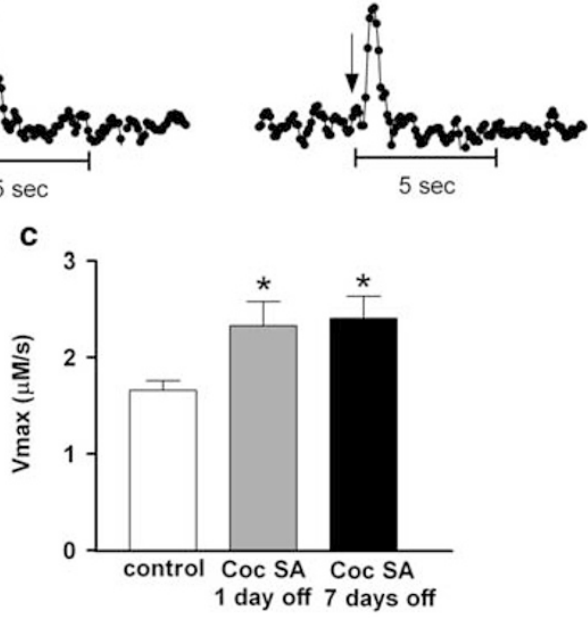

Figure 3 Decreased stimulated DA release and increased DA uptake following cocaine SA and deprivation. (a) Representative neurochemical responses to local electrical stimulation (single pulse applied every $5 \mathrm{~min}$ ) in slices containing the core of the NAc. Left: control; middle: cocaine SA with I day of deprivation; right: cocaine SA with 7 days of deprivation. Following the stimulation (indicated by the arrow), there is an increase in extracellular DA followed by a decrease back to baseline. Each point represents a measurement of DA concentration from one voltammetric scan taken every I00 ms. (b) The peak extracellular DA concentration following electrical stimulation. Responses for naive rats $(n=4)$ are represented by the filled bar and for rats following cocaine binge SA with I $(n=5)$ or $7(n=7)$ days of deprivation by the dark and light gray bars, respectively. Electrically stimulated DA release was significantly decreased $(p<0.00$ I) following cocaine binge SA with I $(p<0.0$ I) or $7(p<0.00$ I) days of deprivation. This decrease is greater following 7 days of deprivation compared to I day of deprivation $(p<0.05$ ). ( $\# p<0.05$, I vs 7 days off; $* p<0.0$ I, I day off vs control; ** $p<0.00$ I, 7 days off vs control). (c) Following cocaine binge SA, DA uptake was significantly increased $(p<0.05)$ compared to naïve animals. Uptake rates were measured following evoked release of endogenous DA and evaluated by the parameter $V_{\max }$ (Wightman et al, 1988). Responses for naïve rats $(n=6)$ are represented by the filled bar and for rats following cocaine SA with I $(n=6)$ or $7(n=7)$ days of deprivation by the dark and light gray bars, respectively $(* p<0.05, I$ or 7 days off $v$ s control).

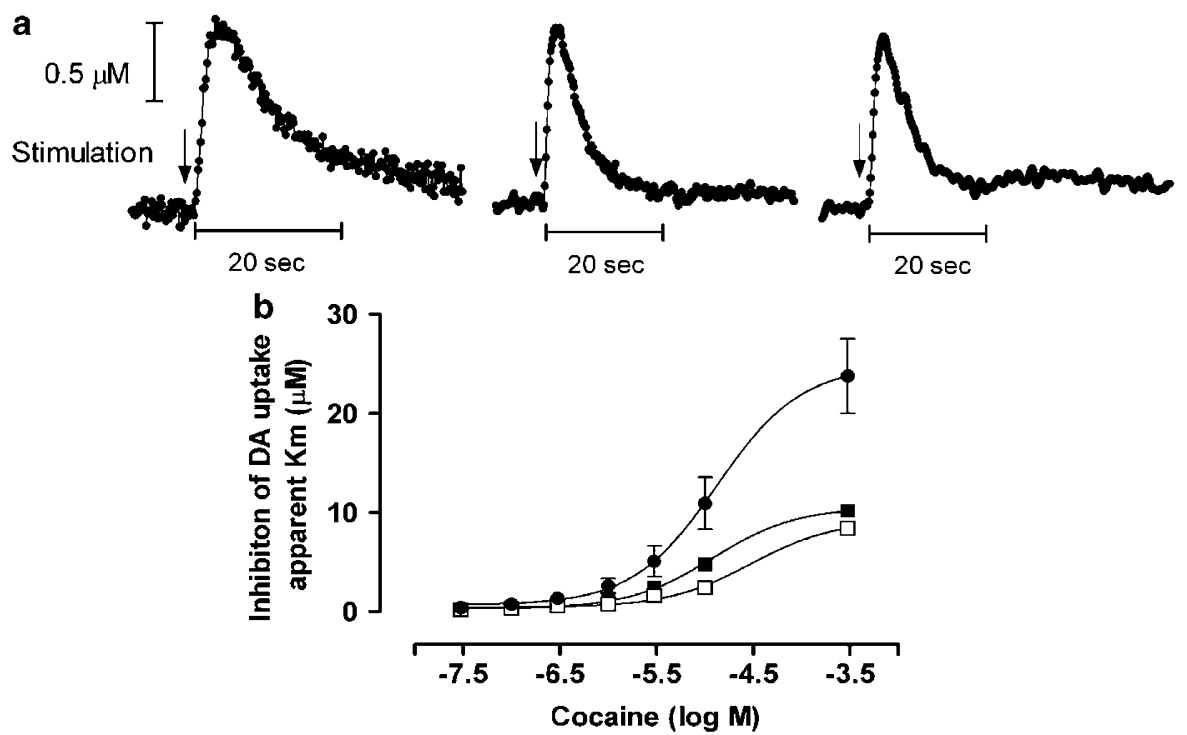

Figure 4 Cocaine is less efficient in inhibiting uptake following cocaine binge SA and deprivation. (a) Representative responses to I0 $\mu M$ cocaine in slices containing the core of the NAc. Left: control; middle: cocaine binge SA with I day of deprivation; right: cocaine binge SA with 7 days of deprivation. Clearance of DA following release is due to DA uptake. Data points are every $100 \mathrm{~ms}$. (b) Cocaine showed a decreased ability to inhibit DA uptake in the NAc core of animals following binge/deprivation SA after I $(n=6)$ or $7(n=7)$ days of deprivation $(p<0.000 \mathrm{I})$, compared to naive animals $(n=6)$. The graph shows the effect of cocaine on DA uptake measured as apparent $K_{m}$, the observed affinity (in $\mu M$ ) of DA for the transporter. $K_{m}$ is equal to the DA concentration at which the reaction rate is half of its maximal value. Data are represented by: naïve animals ( $)$ and animals following cocaine binge SA with I ( $\mathbf{\square})$ or 7 days $(\square)$ of deprivation.

higher concentrations there was a further widening but often a decrease in the amplitude (see Figure 4a, control), probably due to activation of $\mathrm{D} 2$-like release-regulating autoreceptors (Dwoskin and Zahniser, 1986). Following application of $10 \mu \mathrm{M}$ and higher concentrations of cocaine this decrease in the amplitude of DA signal is not observed 
in animals with a binge/deprivation history of SA, most likely because D2-like autoreceptor function is desensitized following exposure to cocaine (see below). A high concentration of cocaine $(30 \mu \mathrm{M})$ in the NAc core dramatically increased the apparent $K_{\mathrm{m}}$ for DA uptake in naïve rats $(24.75 \pm 1.90 \mu \mathrm{M} ; n=6$; Figure $4 \mathrm{~b})$, resulting in overall decreased clearance rates. Surprisingly, cocaine did not have the same effect in animals following a binge/ deprivation history of SA. In these animals, the maximal apparent $K_{\mathrm{m}}$ increased to only $9.22 \pm 0.27 \mu \mathrm{M}(n=6)$ and $11.04 \pm 0.28 \mu \mathrm{M}(n=7)$ following 1 and 7 days of deprivation, respectively (Figure $4 \mathrm{~b}$ ). The effect of cocaine was significantly decreased following both periods of deprivation and a significant interaction between groups over time was found $\left(\mathrm{F}_{10,95}=10.02 ; p<0.0001\right)$.

\section{DA Release-Regulating Autoreceptors are Subsensitive Following Cocaine SA}

The activity of release-regulating autoreceptors was evaluated in the core of the NAc. Increasing concentrations of the DA D2-like receptor agonist quinpirole (1-300 nM) were added to slices at 25-min intervals. The peak in DA release was re-established at each concentration and expressed as percent of control (Figure 5). Quinpirole significantly inhibited DA release in the core of the NAc $\left(\mathrm{F}_{5,78}=44.88\right.$; $p<0.0001)$. The log-concentration extrapolated to the halfmaximal response $\left(\log \mathrm{EC}_{50}\right)$ was $-8.25 \pm 0.25(6 \mathrm{nM})$ for naïve animals $(n=4)$. Following a cocaine binge SA history protocol and 1 or 7 days of deprivation, quinpirole also significantly decreased DA release in the core of the NAc $\left(\log \mathrm{EC}_{50}=-7.82 \pm 0.09 ; 15 \mathrm{nM}\right.$ and $\log \mathrm{EC}_{50}=-8.06 \pm 0.27$; $9 \mathrm{nM}$, respectively). In this situation, cocaine SA history had a significant effect when compared to controls $\left(\mathrm{F}_{2,78}=15.64 ; \quad p<0.0001\right)$, showing a subsensitivity of

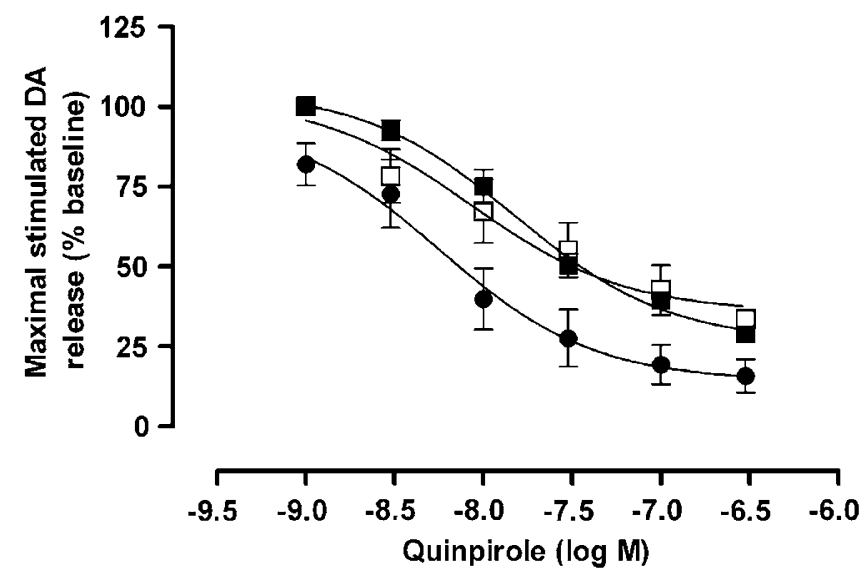

Figure 5 DA release-regulating autoreceptors are subsensitive following cocaine binge SA and deprivation. Concentration-response relationship of quinpirole and maximal evoked DA release in NAc core in naive rats $(n=4)$ and rats following a DT4 schedule of SA with $\mid(n=5)$ and 7 $(n=7)$ days of deprivation. Rats with a SA history showed a desensitized response of inhibitory D2 autoreceptors on DA release after I day $(p<0.0001)$ or 7 days $(p<0.0001)$ of deprivation. Data are represented by: naive animals ( ) and animals following cocaine binge SA with I or 7 days $(\square)$ of deprivation. inhibitory D2 autoreceptors (Figure 5). No interaction between groups was found $\left(\mathrm{F}_{10,78}=0.653 ; p=0.763\right)$.

\section{DISCUSSION}

The present experiments showed that 10 days of binge-like cocaine SA produced a marked decrease in the ability of cocaine to inhibit DA uptake and also caused changes in DA terminal function suggestive of a hypodopaminergic state (see Dackis and Gold, 1985). The changes observed in this study were found at both time points examined (after 1 and 7 days). Previous experiments have shown that the reinforcing effects of cocaine are significantly augmented after 7 days of drug deprivation compared to the 1 day off group (Morgan et al, 2002, 2004). The present data showing that the 1 and 7 day deprivation groups show almost identical changes in DA terminal function indicates that these neurochemical effects do not account for the behavioral results. These data, showing a dramatic loss of cocaine effects on DA, are in contrast to accepted theories that equate increased behavioral response to cocaine with increased DA terminal responsiveness (Kalivas and Duffy, 1993; Suto et al, 2003).

Previous reports have shown enhanced cocaine-induced DA levels using a variety of other dosing protocols and have associated enhanced DA levels with increased cocaine reinforcement (Vezina, 2004). It appears that increased DA is associated with increased reinforcement following a locomotor sensitization producing protocol of experimenter-administered cocaine. However, a simple model of increased DA cannot account for the present results. The protocol used here provides high-intake, 24-h access SA, a procedure that differs significantly from a locomotor sensitizing regimen. Here, we have demonstrated that enhanced DA is not a requirement for elevated reinforcing efficacy of cocaine, and in fact a decreased DA response to cocaine may exist at the same time as increased reinforcement. That is, there is an increase in cocaine reinforcement using a progressive ratio SA schedule after 7 days of deprivation despite a downregulation in basal DA terminal parameters and a markedly decreased sensitivity to cocaine itself. Interestingly, there were similar dopaminergic changes in animals that were not sensitized to the reinforcing effects of cocaine (ie following 1 day of deprivation). Taken together, these results demonstrate that increased DA release in the NAc is not a necessary part of increased cocaine reinforcement and other hypotheses must be examined.

In sharp contrast to the behaviorally demonstrated increase in the reinforcing efficacy of cocaine, cocaine failed to increase extracellular DA concentrations in the core and shell of the NAc of freely moving rats. When the terminals were studied in more detail with voltammetry in brain slices containing the NAc core, the ability of cocaine to inhibit DA uptake was also severely curtailed following cocaine binge SA and deprivation (at both 1 and 7 days of deprivation). These findings are of particular interest because uptake has been shown not to change in limitedaccess cocaine SA paradigms, even with prolonged access times (Ahmed et al, 2003). In fact, some microdialysis experiments have shown the same or greater effect of 
cocaine on extracellular DA levels following chronic administration (Akimoto et al, 1989; Kalivas and Duffy, 1990, 1993; Zapata et al, 2003). Thus, it appears that continuous access is required to produce tolerance of DA uptake to the effects of cocaine. The demonstrated increase in the reinforcing efficacy of cocaine on a PR schedule after 7 days of deprivation occurs in spite of the decreased ability of cocaine to inhibit DA uptake in the core NAc, and suggests that the simple hypothesis that increased DA in the NAc leads to increased reinforcement is incomplete.

Each of the DA parameter changes measured by microdialysis and voltammetry in the present study are consistent with a compensatory downregulation of the DA system, presumably in response to elevated extracellular DA levels during cocaine SA. Measured with microdialysis, baseline extracellular DA concentrations were significantly decreased following cocaine binge SA and 1 or 7 days of deprivation. Voltammetry also showed that electrically stimulated DA release was significantly decreased after either deprivation period. Decreased DA release has been described previously following withdrawal from unlimitedaccess cocaine SA (Weiss et al, 1992) or chronic daily administration (Parsons et al, 1991), although the opposite has also been found (Maisonneuve et al, 1995; Chefer and Shippenberg, 2002). Thus, a hypodopaminergic status of DA terminals is present in the NAc core following this protocol of cocaine binge SA and deprivation.

The functional rate of DA uptake was found to be increased following binge-like cocaine SA, regardless of deprivation period. The more rapid clearance of extracellular DA would lead to a decrease in extracellular DA. In previous studies using rodents, repeated administration of cocaine has been shown many times to alter DAT measures, although the nature of these changes has been inconsistent and seems to be influenced by many factors, including mode and pattern of administration, dose, treatment duration, and length of deprivation period (Kuhar and Pilotte, 1996; Chefer and Shippenberg, 2002; Gerrits et al, 2002). In human and non-human primate brains, data concerning changes in DAT binding levels have been conflicting, with increases (Staley et al, 1994; Malison et al, 1998; Letchworth et al, 2001) and decreases (Hurd and Herkenham, 1993) documented. There is also literature showing that with repeated cocaine administration, the affinity of the transporter is not changed, while the density or $B_{\max }$ (roughly equivalent to our $V_{\max }$ ) is increased (eg Claye et al, 1995). Here, we found that the rate of DA uptake is increased by binge cocaine SA and deprivation, and this also contributes to the hypodopaminergic status of DA terminals in the NAc core.

Autoreceptors controlling DA release from terminals in the NAc core were found to be subsensitive to the inhibitory effect of quinpirole on electrically evoked DA release to an equal extent in both deprivation groups. This is an adaptation which might lead to greater DA release, but in this case it did not. DA release is controlled by many factors, including synthesis, vesicular packaging, presynaptic membrane ionic properties, and exocytotic machinery to name a few. Therefore, it is possible for autoreceptors to have less sensitivity to agonist activation and still have less DA released following electrical stimulation. Subsensitivity of autoreceptors may be explained by the normal process of
G-protein-coupled receptor desensitization/downregulation following prolonged stimulation by the endogenous agonist, in this case DA (Kim et al, 2001). Several reports have shown that experimenter-administered, repeated, intermittent cocaine treatment regimens that include an deprivation period produce locomotor sensitization and result in functional subsensitivity of release-modulating autoreceptors in the caudate-putamen (Jones et al, 1996) and NAc (Yi and Johnson, 1990; Davidson et al, 2000; Chefer and Shippenberg, 2002). Decreased reactivity of DA cell bodies to D2 autoreceptor regulation has also been found following cocaine SA (Zhang et al, 1997; Gao et al, 1998; Marinelli et al, 2003).

Both the shell and core of the NAc have been implicated in the behavioral effects of psychostimulant drugs. One idea is that the shell mediates the rewarding effects of drugs of abuse while the core mediates the locomotor stimulant effects (Carlezon and Wise, 1996; Ikemoto et al, 1997; Boye et al, 2001; Sellings and Clarke, 2003). Cocaine and amphetamine appear to preferentially increase glucose utilization in the shell compared with the core of the Nac, and morphine, nicotine, cocaine, and amphetamine preferentially increased extracellular DA in the shell over the core (Pontieri et al, 1995, 1996). In contrast, a number of papers suggest a preferential involvement of the NAc core in morphological changes associated with sensitization ( $\mathrm{Li}$ et al, 2004), acquisition of opiate SA (Alderson et al, 2001; Hutcheson et al, 2001), and with relapse to cocaine use (McFarland and Kalivas, 2001). It would appear that both regions of the NAc subserve different roles in the reinforcing effects of drugs of abuse. Therefore, we examined DA in both regions in the present microdialysis study. Although the core was the main focus, it was important to rule out any major differences in DA regulation by cocaine $\mathrm{SA}$ and deprivation between these two regions that might explain the behavioral differences. Identical patterns of DA system downregulation were seen in the core and shell of the Nac; therefore, we conclude that cocaine is unable to elevate DA in either subregion of the NAc.

With the high intakes of cocaine that are achieved with this discrete trials SA procedure, the possibility that neurotoxicity may occur cannot be ignored; however, we feel that it is unlikely. For instance, during the behavioral sessions we did not observe evidence of behavioral toxicity (weight loss, loss of diurnal cycle, seizures, huddling, and other outward signs of illness). Moreover, the hypodopaminergic state observed in this study is not consistent with a loss of DA terminals, in fact, a significantly greater DA uptake rate was found following SA and deprivation. Therefore, neurotoxicity cannot account for the changes in DA system function found in the present study.

Overall, we conclude that DA neurotransmission in the NAc following binge-deprivation SA is hypodopaminergic. This is in contrast to many studies of limited-access cocaine SA and suggests that extended access and high intake of cocaine produces a different profile of adaptations. Seven days of deprivation produces a greatly increased reinforcing efficacy of cocaine, but surprisingly DA terminals in the core NAc were not altered in a manner that would provide a greater DA elevation with cocaine, and in fact just the opposite occurred. Interestingly, the DA terminals were 
low-functioning and highly insensitive to the effects of cocaine.

There are at least three possibilities to consider. First, the progressive decrease in electrically stimulated DA release found at 7 days of deprivation may be indicative of a general decrease in DA signaling that is aversive to the animal, and the relatively small increment in extracellular DA that may be induced by cocaine may have a larger value than normal. In other words, in a hypodopaminergic state, a particular dose of cocaine may maintain more responses on a PR schedule than it would in an animal with a normal dopaminergic state. Second, and related, is the possibility that supersensitivity of postsynaptic DA receptors develops over the 7 days of deprivation in response to low DA output to produce a larger response to the presumably lesser increase in DA following cocaine. Finally, and most likely, DA terminals in the NAc core may not be the location of adaptations promoting the increase in reinforcing efficacy of cocaine. Locomotor sensitization appears to require alterations in glutamate neurotransmission in the ventral tegmental area; similarly, neurotransmitters other than DA or locations other than the NAc could be involved in the increased response to cocaine.

Clearly the mechanisms underlying the acute reinforcing effects of cocaine and the process of addiction are different. These are early days of examining the neurobiology of the addictive process using SA models rather than examining the acute reinforcing effects. Here, we demonstrate subsensitivity at the initial site of action of cocaine, and downstream elements and other neurotransmitter systems are clearly implicated in the alterations in cocaine reinforcement produced by this animal model.

\section{ACKNOWLEDGEMENTS}

This research was supported by DA 06634 (DCSR and SRJ), DA 14030 (DCSR), DA 13957 (DM), and DA 01881 (SRJ).

\section{REFERENCES}

Ahmed SH, Lin D, Koob GF, Parsons LH (2003). Escalation of cocaine self-administration does not depend on altered cocaineinduced nucleus accumbens dopamine levels. J Neurochem 86: $102-113$.

Akimoto K, Hamamura T, Otsuki S (1989). Subchronic cocaine treatment enhances cocaine-induced dopamine efflux, studied by in vivo intracerebral dialysis. Brain Res 490: 339-344.

Alderson HL, Parkinson JA, Robbins TW, Everitt BJ (2001). The effects of excitotoxic lesions of the nucleus accumbens core or shell regions on intravenous heroin self-administration in rats. Psychopharmacology 53: 455-463.

Bardo MT (1998). Neuropharmacological mechanisms of drug reward: beyond dopamine in the nucleus accumbens. Crit Rev Neurobiol 12: 37-67.

Bibb JA, Chen J, Taylor JR, Svenningsson P, Nishi A, Snyder GL et al (2001). Effects of chronic exposure to cocaine are regulated by the neuronal protein Cdk5. Nature 410: 376-380.

Boye SM, Grant RJ, Clarke PB (2001). Disruption of dopaminergic neurotransmission in nucleus accumbens core inhibits the locomotor stimulant effects of nicotine and D-amphetamine in rats. Neuropharmacology 40: 792-805.

Budygin EA, Phillips PE, Wightman RM, Jones SR (2001). Terminal effects of ethanol on dopamine dynamics in rat nucleus accumbens: an in vitro voltammetric study. Synapse 42 : 77-79.

Carlezon Jr WA, Wise RA (1996). Rewarding actions of phencyclidine and related drugs in nucleus accumbens shell and frontal cortex. J Neurosci 16: 3112-3122.

Chefer VI, Shippenberg TS (2002). Changes in basal and cocaineevoked extracellular dopamine uptake and release in the rat nucleus accumbens during early deprivation from cocaine: quantitative determination under transient conditions. Neuroscience 112: 907-919.

Claye LH, Akumme HC, Davis MD, DeMattos S, Soliman KF (1995). Behavioral and neurochemical changes in the dopaminergic system after repeated cocaine administration. Mol Neurobiol 11: 55-66.

Cragg SJ, Rice ME (2004). DAncing past the DAT at a DA synapse. Trends Neurosci 27: 270-277.

Dackis CA, Gold MS (1985). New concepts in cocaine addiction: the dopamine depletion hypothesis. Neurosci Biohehav Rev 9: 469-477.

Dackis CA, O'Brien CP (2001). Cocaine dependence: a disease of the brain's reward centers. J Subst Abuse Treat 21: 111-117.

Davidson C, Ellinwood EH, Lee TH (2000). Altered sensitivity of dopamine autoreceptors in rat accumbens 1 and 7 days after intermittent or continuous cocaine withdrawal. Brain Res Bull 51: 89-93.

Di Chiara G (1999). Drug addiction as dopamine-dependent associative learning disorder. Eur J Pharmacol 375: 13-30.

Dwoskin LP, Zahniser NR (1986). Robust modulation of $\left[{ }^{3} \mathrm{H}\right]$ dopamine release from rat striatal slices by $\mathrm{D}-2$ dopamine receptors. J Pharmacol Exp Ther 239: 442-453.

Freeman WM, Brebner K, Patel KM, Lynch WJ, Roberts DC, Vrana KE (2002). Repeated cocaine self-administration causes multiple changes in rat frontal cortex gene expression. Neurochem Res 27: 1181-1192.

Gao WY, Lee TH, King GR, Ellinwood EH (1998). Alterations in baseline activity and quinpirole sensitivity in putative dopamine neurons in the substantia nigra and ventral tegmental area after withdrawal from cocaine pretreatment. Neuropsychopharmacology 18: 222-232.

Gawin FH (1991). Cocaine addiction: psychology and neurophysiology. Science 251: 1580-1586.

Gerrits MA, Petromilli P, Westenberg HG, Di Chiara G, van Ree JM (2002). Decrease in basal dopamine levels in the nucleus accumbens shell during daily drug-seeking behaviour in rats. Brain Res 924: 141-150.

Goldstein RZ, Volkow ND (2002). Drug addiction and its underlying neurobiological basis: neuroimaging evidence for the involvement of the frontal cortex. Am J Psychiatry 159: $1642-1652$.

Heikkila RE, Orlansky H, Mytilineou C, Cohen G (1975). Amphetamine: evaluation of $d$ - and $l$-isomers as releasing agents and uptake inhibitors for $3 \mathrm{H}$-dopamine and $3 \mathrm{H}$-norepinephrine in slices of rat neostriatum and cerebral cortex. J Pharmacol Exp Ther 194: 47-56.

Hutcheson DM, Parkinson JA, Robbins TW, Everitt BJ (2001). The effects of nucleus accumbens core and shell lesions on intravenous heroin self-administration and the acquisition of drug-seeking behaviour under a second-order schedule of heroin reinforcement. Psychopharmacology 153: 464-472.

Horn AS (1990). Dopamine uptake: a review of progress in the last decade. Prog Neurobiol 34: 387-400.

Hurd YL, Herkenham M (1993). Molecular alterations in the neostriatum of human cocaine addicts. Synapse 13: 357-369.

Ikemoto S, Glazier BS, Murphy JM, McBride WJ (1997). Role of dopamine D1 and D2 receptors in the nucleus accumbens in mediating reward. $J$ Neurosci 17: 8580-8587.

Jones SR, Lee TH, Wightman RM, Ellinwood EH (1996). Effects of intermittent and continuous cocaine administration on dopamine 
release and uptake regulation in the striatum: in vitro voltammetric assessment. Psychopharmacology 126: 331-338.

Kalivas PW, Duffy P (1990). Effect of acute and daily cocaine treatment on extracellular dopamine in the nucleus accumbens. Synapse 5: 48-58.

Kalivas PW, Duffy P (1993). Time course of extracellular dopamine and behavioral sensitization to cocaine. I. Dopamine axon terminals. J Neurosci 13: 266-275.

Kennedy RT, Jones SR, Wightman RM (1992). Dynamic observation of dopamine autoreceptor effects in rat striatal slices. J Neurochem 59: 449-455.

Kim KM, Valenzano KJ, Robinson SR, Yao WD, Barak LS, Caron MG (2001). Differential regulation of the dopamine D2 and D3 receptors by $\mathrm{G}$ protein-coupled receptor kinases and betaarrestins. J Biol Chem 276: 37409-37414.

Koob GF, Caine B, Markou A, Pulvirenti L, Weiss F (1994). Role for the mesocortical dopamine system in the motivating effects of cocaine. NIDA Res Monogr 145: 1-18.

Kuhar MJ, Pilotte NS (1996). Neurochemical changes in cocaine withdrawal. Trends Pharmacol Sci 17: 260-264.

Leshner AI, Koob GF (1999). Drugs of abuse and the brain. Proc Assoc Am Physicians 111: 99-108.

Letchworth SR, Nader MA, Smith HR, Friedman DP, Porrino LJ (2001). Progression of changes in dopamine transporter binding site density as a result of cocaine self-administration in rhesus monkeys. J Neurosci 21: 2799-2807.

Li Y, Acerbo MJ, Robinson TE (2004). The induction of behavioural sensitization is associated with cocaine-induced structural plasticity in the core (but not shell) of the nucleus accumbens. Eur J Neurosci 20: 1647-1654.

Maisonneuve IM, Ho A, Kreek MJ (1995). Chronic administration of a cocaine 'binge' alters basal extracellular levels in male rats: an in vivo microdialysis study. J Pharmacol Exp Ther 272: 652-657.

Malison RT, Best SE, van Dyck CH, McCance EF, Wallace EA, Laruelle $\mathrm{M}$ et al (1998). Elevated striatal dopamine transporters during acute cocaine deprivation as measured by [123I] betaCIT SPECT. Am J Psychiatry 155: 832-834.

Marinelli M, Cooper DC, Baker LK, White FJ (2003). Impulse activity of midbrain dopamine neurons modulates drug-seeking behavior. Psychopharmacology 168: 84-98.

McFarland K, Kalivas PW (2001). The circuitry mediating cocaineinduced reinstatement of drug-seeking behavior. J Neurosci 21: $8655-8663$.

Morgan D, Brebner K, Lynch WJ, Roberts DC (2002). Increases in the reinforcing efficacy of cocaine after particular histories of reinforcement. Behav Pharmacol 13: 389-396.

Morgan D, Roberts DC (2004). Sensitization to the reinforcing effects of cocaine following binge-abstinent self-administration. Neurosci Biobehav Rev 27: 803-812.

Morgan D, Smith MA, Roberts DC (2004). Binge self-administration and deprivation produces sensitization to the reinforcing effects of cocaine in rats. Psychopharmacology, DOI 15322729.

Onali P, Olianas MC (1989). Involvement of adenylate cyclase inhibition in dopamine autoreceptor regulation of tyrosine hydroxylase in rat nucleus accumbens. Neurosci Lett 102: 91-96.

Palij P, Bull DR, Sheehan MJ, Millar J, Stamford J, Kruk ZL et al (1990). Presynaptic regulation of dopamine release in corpus striatum monitored in vitro in real time by fast cyclic voltammetry. Brain Res 509: 172-174.

Parsons LH, Smith AD, Justice Jr JB (1991). Basal extracellular dopamine is decreased in the rat nucleus accumbens during deprivation from chronic cocaine. Synapse 9: 60-65.

Phillips PE, Johns JM, Lubin DA, Budygin EA, Gainetdinov RR, Lieberman JA et al (2003). Presynaptic dopaminergic function is largely unaltered in mesolimbic and mesostriatal terminals of adult rats that were prenatally exposed to cocaine. Brain Res 961: 63-72.
Pontieri FE, Tanda G, Di Chiara G (1995). Intravenous cocaine, morphine, and amphetamine preferentially increase extracellular dopamine in the 'shell' as compared with the 'core' of the rat nucleus accumbens. Proc Natl Acad Sci USA 92: 12304-12308

Pontieri FE, Tanda G, Orzi F, Di Chiara G (1996). Effects of nicotine on the nucleus accumbens and similarity to those of addictive drugs. Nature 382: 255-257.

Ritz MC, Lamb RJ, Goldberg SR, Kuhar MJ (1987). Cocaine receptors on dopamine transporters are related to self-administration of cocaine. Science 237: 1219-1223.

Roberts DC, Brebner K, Vincler M, Lynch WJ (2002). Patterns of cocaine self-administration in rats produced by various access conditions under a discrete trials procedure. Drug Alcohol Depend 67: 291-299.

Roberts DC, Corcoran ME, Fibiger HC (1977). On the role of ascending catecholaminergic systems in intravenous self-administration of cocaine. Pharmacol Biochem Behav 6: 615-620.

Sellings LH, Clarke PB (2003). Segregation of amphetamine reward and locomotor stimulation between nucleus accumbens medial shell and core. J Neurosci 23: 6295-6303.

Staley JK, Hearn WL, Ruttenber AJ, Wetli CV, Mash DC (1994). High affinity cocaine recognition sites on the dopamine transporter are elevated in fatal cocaine overdose victims. J Pharmacol Exp Ther 271: 1678-1685.

Suto N, Tanabe LM, Austin JD, Creekmore E, Vezina P (2003). Previous exposure to VTA amphetamine enhances cocaine selfadministration under a progressive ratio schedule in an NMDA, AMPA/kainate, and metabotropic glutamate receptor-dependent manner. Neuropsychopharmacology 28: 629-639.

Vezina P (2004). Sensitization of midbrain dopamine neuron reactivity and the self-administration of psychomotor stimulant drugs. Neurosci Biobehav Rev 27: 827-839.

Volkow ND, Wang GJ, Fowler JS, Logan J, Gatley SJ, Hitzemann R et al (1997). Decreased striatal dopaminergic responsiveness in detoxified cocaine-dependent subjects. Nature 386: 830-833.

Weiss F, Markou A, Lorang MT, Koob GF (1992). Basal extracellular dopamine levels in the nucleus accumbens are decreased during cocaine withdrawal after unlimited-access selfadministration. Brain Res 593: 314-318.

White FJ, Kalivas PW (1998). Neuroadaptations involved in amphetamine and cocaine addiction. Drug Alcohol Depend 51: 141-153.

Wieczorek W, Kruk ZL (1995). Influences of neuronal uptake and D2 autoreceptors on regulation of extracellular dopamine in the core, shell and rostral pole of the rat nucleus accumbens. Brain Res 699: 171-182.

Wightman RM, Amatore C, Engstrom RC, Hale PD, Kristensen EW, Kuhr WG et al (1988). Real-time characterization of dopamine overflow and uptake in the rat striatum. Neuroscience 25: $513-523$.

Yi SJ, Johnson KM (1990). Chronic cocaine treatment impairs the regulation of synaptosomal $3 \mathrm{H}-\mathrm{DA}$ release by $\mathrm{D} 2$ autoreceptors. Pharmacol Biochem Behav 36: 457-461.

Zapata A, Chefer VI, Ator R, Shippenberg TS, Rocha BA (2003). Behavioural sensitization and enhanced dopamine response in the nucleus accumbens after intravenous cocaine self-administration in mice. Eur J Neurosci 17: 590-596.

Zhang XF, Hu XT, White FJ, Wolf ME (1997). Increased responsiveness of ventral tegmental area dopamine neurons to glutamate after repeated administration of cocaine or amphetamine is transient and selectively involves AMPA receptors. J Pharmacol Exp Ther 281: 699-706.

Zhou Y, Spangler R, Ho A, Kreek MJ (2003). Increased CRH mRNA levels in the rat amygdala during short-term withdrawal from chronic 'binge' cocaine. Brain Res Mol Brain Res 114: 73-79. 